\title{
Chemotypic Variation in Clove Oil and Lemongrass Oil Obtained from Three Different Geographical Locations of India
}

\section{Priya ES*, Selvan PS and Yavanarajan A}

Department of Pharmaceutical Technology, Anna University BIT Campus, Tiruchirappalli-620 024, Tamil Nadu, India

\begin{abstract}
Clove buds and lemongrass leaves were collected from three different locations of India and the essential oil was separated by hydrodistillation procedure. The essential oils were studied for its variation in physical properties and chemical composition. Chemical analysis by GC-MS evidenced that the main components of clove oil (CLV) were eugenol (78.5-87.7\%) and caryophyllene (12.3-20.2\%) and the main components of lemongrass oil (LGR) were citral in the form of neral and geranial (24.3-83.9\%) and (+) camphor (12.07-30.62\%). The lemon grass oil collected from Ootacamund hills, Tamilnadu have shown components like Limonene $(2.7 \%)$, isocamphene $(5.1 \%)$, endo isocamphene $(5.3 \%)$, p-cymene $(2.4 \%)$ and citronellol (1.73\%) among which isocamphene and endo isocamphene were found to be new chemotypes. (+) fenchone was present in the range $5.6-7.76 \%$ in lemongrass oil collected from two different locations. Isopiperitone $(6.23 \%)$ and geranyl butyrate $(3.37 \%)$ were found to be new chemotypes in the essential oil obtained from Bhopal, Madhya Pradesh. Thus the results have shown variation in chemical composition and identification of new chemotypes in both clove oil as well as lemongrass oil collected from three different locations of India which may be due to the change in geographical conditions.
\end{abstract}

Keywords: Essential oil; Clove oil; Lemongrass oil; Eugenol; Caryophyllene; Citral

Abbreviations: CLV:Clove Oil; LGR:Lemongrass Oil; GC-MS:Gas Chromatography-Mass Spectrometry

\section{Introduction}

Essential oils characterized by wonderful scents are concentrated volatile aromatic compounds produced by various plant sources. Each of these complex precious liquids is extracted from a particular species of plant type. Each plant species originates in certain regions of the world, with particular environmental conditions and neighboring fauna and flora. The result is a very diverse library of aromatic compounds, with some essential oils being made up of more than one hundred distinct organic chemicals. More than the commercial importance of the variability in yield and composition of essential oils, it also becomes highly essential when the volatiles are used as chemotaxonomic tools. Thus the knowledge of the factors that determine the chemical variability and yield for essential oils remains very important. Factors that influence the production and composition of essential oils in include (a) physiological variations (b) environmental conditions (c) geographic variations (d) genetic factors and evolution (e) political/social conditions and also (f) amount of plant material/ space and manual labour needs. There are innumerable examples of the occurrence of geographic variations of the yield and composition of volatiles. The different essential oil compositions of a species found for different origins reflect the different environmental conditions of each particular location and culture conditions (different altitudes, different solar exposition, different soil types, etc.) [1]. The literature reveals that the intraprovenance variation for content and chemical composition has been analyzed in Eucalyptus oils among different districts of Punjab, India [2]. Similar studies have been reported on chemical variation of essential oils with respect to different geographical locations [3-5]. Clove oil has been used in human medicine as topical anesthetic, particularly in dentistry [6], as an agent for the treatment of inflammatory diseases and as radical scavengers due to its antioxidant properties [7]. Clove oil has been used in aromatherapy as mouth sterilizer or painkiller [8]. Lemongrass oil has various medicinal, herbal and therapeutic properties. It is expected to have analgesic, antibacterial, carminative, deodorizing, febrifuge, fungicidal, antiseptic, antidepressant, astringent, diuretic, galactogogue, antipyretic, antimicrobial and sedative properties. Its fungicidal properties have been already well reported [9]. Lemongrass oil is a good insect repellant [10]. Biosynthesis of secondary metabolites, in particular essential oil, even though determined genetically, is strongly affected by ontogenetic and environmental factors [11-13]. Thus considering these facts the possibility of geographical condition for the compositional variation of essential oils the present study was conducted by studying the physical properties and chemical composition of clove oil and lemongrass oil by GC-MS analysis. The objective of the study is to identify and report the chemical variation of essential oils like clove oil and lemon grass oil with respect to change in geographical locations.

\section{Materials and Methods}

\section{Extraction of essential oils}

The Clove bud phytosamples were collected from three different sources of India: Ootacamund hills of Tamil Nadu, Nainital Hills of Uttar Pradesh and Munnar of Kerala. The Lemongrass leaf samples were collected from Bhopal of Madhya Pradesh, Ootacamund hills of Tamil Nadu and Azhapuzha of Kerala. The voucher specimen of all the samples were deposited at Raninat herbarium, Centre for molecular systematics, St. Joseph's college (campus), Tiruchirappalli , Essential oils were extracted by initial crushing followed by hydrodistillation.

*Corresponding author: E Sanmuga Priya, Department of Pharmaceutical Technology, Anna University BIT Campus, Tiruchirappalli-620 024, Tamil Nadu, India, Tel: 0431- 2407978; E-mail: sanmug77@gmail.com

Received August 20, 2015; Accepted September 21, 2015; Published September 24, 2015

Citation: Priya ES, Selvan PS, Yavanarajan A (2015) Chemotypic Variation in Clove Oil and Lemongrass Oil Obtained from Three Different Geographical Locations of India. J Pharmacogn Nat Prod 1: 102. doi:10.4172/2472-0992.1000102

Copyright: $\odot 2015$ Priya ES, et al. This is an open-access article distributed under the terms of the Creative Commons Attribution License, which permits unrestricted use, distribution, and reproduction in any medium, provided the original author and source are credited. 
Citation: Priya ES, Selvan PS, Yavanarajan A (2015) Chemotypic Variation in Clove Oil and Lemongrass Oil Obtained from Three Different Geographical Locations of India. J Pharmacogn Nat Prod 1: 102. doi:10.4172/2472-0992.1000102

\section{Analysis of physical and chemical properties}

The specific gravity of various samples was yielded out using a pycnometer, while optical rotation and refractive index were determined using a polarimeter and Abbe's refractometer.

\section{GC-MS equipment}

The analysis was performed in GC-MS Instrument named SHIMADZU-QP 2010 PLUS. The column used was RXi-5MS, L: $30 \mathrm{~m}$, T: $0.25 \mu \mathrm{m}, \mathrm{d}: 0.25 \mathrm{~mm}$. The method used for the Clove oil analysis is as follows. The column temperature was maintained at $100^{\circ} \mathrm{C}$. The flow rate was retained at $5.6 \mathrm{ml} / \mathrm{min}$. The temperature suite is devised as initial $100^{\circ} \mathrm{C}$ for $2 \mathrm{~min}$, rate: $6^{\circ} \mathrm{C} / \mathrm{min}, 200^{\circ} \mathrm{C}$ for $1 \mathrm{~min}$, rate: $20^{\circ} \mathrm{C} / \mathrm{min}$ and $250^{\circ} \mathrm{C}$ for $2 \mathrm{~min}$. The sample preparation was done by dissolving $0.2 \mu \mathrm{l}$ Clove oil in $50 \mathrm{ml}$ Acetonitrile (solvent). The system of analysis of the Lemongrass oil samples were devised as follows. The column temperature was maintained at $50^{\circ} \mathrm{C}$. The stream rate was sustained at $11 \mathrm{ml} / \mathrm{min}$. The temperature suite was formulated as: initial $50^{\circ} \mathrm{C}$ for 1 min, $100^{\circ} \mathrm{C}$ for $1 \mathrm{~min}$, rate: $10^{\circ} \mathrm{C} / \mathrm{min}$ and $150^{\circ} \mathrm{C}$ for $1 \mathrm{~min}$, rate: $10^{\circ} \mathrm{C} /$ $\mathrm{min}$. The sample preparation was done by dissolving $0.2 \mu \mathrm{l}$ Clove oil in $50 \mathrm{ml}$ methanol (solvent).

\section{Results and Discussion}

The physical properties like refractive index, optical rotation, boiling range and weight per ml were calculated from the corresponding methods of determination for the various samples extracted from various sources. The variations in physical properties of Clove oil and Lemongrass oil are well elucidated in Tables 1 and 2. Analysis of chemical composition of the samples was performed using GC-MS. In the analysis of Clove oil, the major peaks were identified as Eugenol at the retention time 9.4 and Caryophyllene at 10.9. Thus it is evident that the Eugenol and the Caryophyllene are the major constituents of the Clove bud essential oil which concurs with the dissertations of various researchers [14-16] (Table 3). Among the three locations, Eugenol was present in higher concentration (in percentage) in the essential oil isolated from buds collected from Munnar, Kerala and Caryophyllene was present in higher concentration (in percentage) in the oil isolated from the buds collected from Ootacamund hills, Tamilnadu when compared with other locations. The other components were a-Humulene $(2.26 \%)$ in CLV01 and 3-carene (1.24\%) in CLV03, where the latter was found to be new chemotype in clove oil (Figure 1). In GC-MS analysis of Lemongrass oil, it was found that the major peaks were at the retention times 10.29 and 10.775 representing Neral and Geranial respectively. Thus Neral and Geranial being the isomers of Citral, comprises the role as the major constituent of the Lemongrass oil confirming to the literature [17-19]. The other major components present were Limonene (2.7\%), isocamphene (5.1\%), endo isocamphene $(5.3 \%), \mathrm{p}$-cymene $(2.4 \%)$, citronellol (1.73\%) and linalyl acetate $(1.35 \%)$. Isocamphene and endo isocamphene were found to be new chemotypes in LGR02 (Table 4). (+) fenchone was present in the range 5.6-7.76\% in lemongrass oil collected from two different locations (LGR 01 and LGR 02). Isopiperitone (6.23\%) and geranyl butyrate (3.37\%) were found to be new chemotypes in the essential oil obtained from Bhopal, Madhya Pradesh (LGR 03) (Figure 2). There is strong variation in the composition of essential oils obtained from lemongrass leaves collected from three different locations. The concentration of citral (in percentage) was high in the lemongrass leaves collected from Kerala when compared to other locations, whereas the oil obtained from Ootacamund hills have shown additional number of components
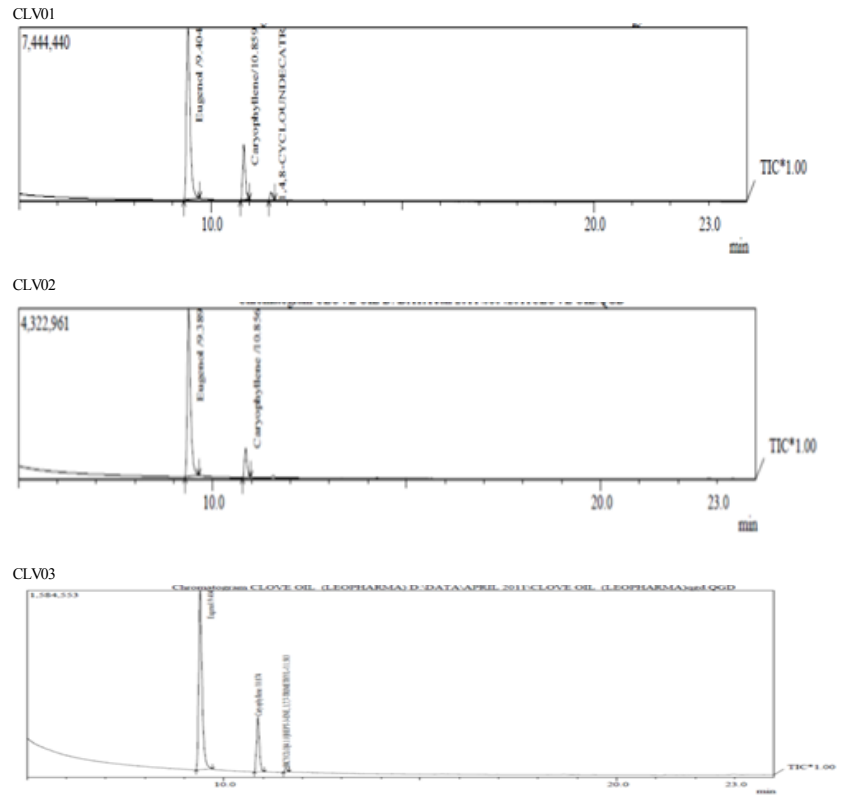

Figure 1: GC chromatograms of clove oil obtained from three different locations of India.

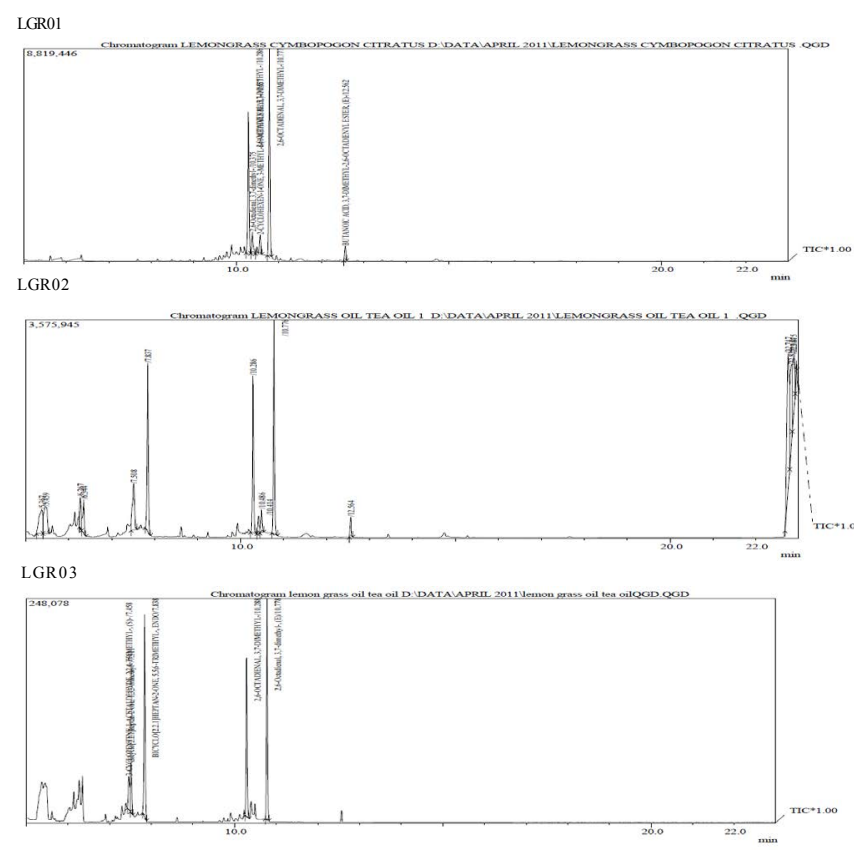

Figure 2: GC chromatograms of lemongrass oil obtained from three different locations of India.

and new chemotypes when compared to other oils collected from other two locations. The change in composition of major constituents of Clove oil and Lemongrass oil were correlated with their geographical conditions. The percentage composition of the Eugenol and Citral in essential oils obtained from Kerala was relatively in higher percentage than other two sources which may be due to the promising climatic conditions (tropical wet climate, wet temperate vegetation, red loamy soil with annual temperature and rainfall $22.5-25^{\circ} \mathrm{C}$ and $400-800 \mathrm{~cm}$ respectively) that might have inclined the higher percentage of Eugenol in the Clove oil and Citral in Lemongrass oil. 
Citation: Priya ES, Selvan PS, Yavanarajan A (2015) Chemotypic Variation in Clove Oil and Lemongrass Oil Obtained from Three Different Geographical Locations of India. J Pharmacogn Nat Prod 1: 102. doi:10.4172/2472-0992.1000102

Page 3 of 4

\begin{tabular}{|c|c|c|c|}
\hline Characteristics & Sample CLV 01 & Sample CLV 02 & $\begin{array}{c}\text { Munnar, } \\
\text { Kerala }\end{array}$ \\
\hline Location & $\begin{array}{c}\text { Nainital Hills, } \\
\text { Uttar Pradesh }\end{array}$ & 1.053 \\
\hline Weight/ml & 1.042 & 1.532 \\
\hline Refractive Index & 1.527 & $253.4-254.1^{\circ} \mathrm{C}$ \\
\hline Boiling Range & $252.2-253.5^{\circ} \mathrm{C}$ & 1.534 \\
\hline Optical Rotation & $-0.78^{\circ}$ & $-1.02^{\circ}$ \\
\hline
\end{tabular}

Table 1: Analysis of physical properties of clove oil collected from three different locations of India.

\begin{tabular}{|c|c|c|c|}
\hline Characteristics & Sample LGR 01 & Sample LGR 02 \\
\hline Location & $\begin{array}{c}\text { Azhapuzha, } \\
\text { Kerala }\end{array}$ & $\begin{array}{c}\text { Ootacamund Hills, } \\
\text { Tamil Nadu }\end{array}$ \\
\hline Weight/ml & 0.894 & 0.884 & $\begin{array}{c}\text { Bhopal, } \\
\text { Madhya Pradesh }\end{array}$ \\
\hline Refractive Index & 1.492 & 1.487 & 0.873 \\
\hline Boiling Range & $259.7-260.2^{\circ} \mathrm{C}$ & $258.4-259.9^{\circ} \mathrm{C}$ \\
\hline Optical Rotation & $-3.2^{\circ}$ & $-4.3^{\circ}$ \\
\hline
\end{tabular}

Table 2: Analysis of physical properties of Lemongrass oil collected from various locations of India.

\begin{tabular}{|c|c|c|c|c|}
\hline S.No & Components & Mol wt & CLV 01 & CLV 02 \\
\hline 1. & Eugenol & 164 & $79.7 \%$ & $82.72 \%$ \\
\hline 2. & Caryophyllene & 204 & $18.03 \%$ & $11.32 \%$ \\
\hline 3. & a-Humulene & 204 & $2.26 \%$ & - \\
\hline 4. & 3-carene & 136 & - & - \\
\hline
\end{tabular}

Table 3: Variation in chemical composition of clove oil obtained from three different locations of India.

\begin{tabular}{|c|c|c|c|c|c|}
\hline S.No. & Components & Mol wt & LGR01 & LGR02 & LGR03 \\
\hline 1. & Isocamphane & 138 & - & $5.01 \%$ & - \\
\hline 2. & Endo-isocamphane & 138 & - & $5.3 \%$ & - \\
\hline 3. & p-cymene & 134 & - & $2.4 \%$ & - \\
\hline 4. & (+) Limonene & 136 & - & $2.7 \%$ & - \\
\hline 5. & (+) Fenchone & 152 & $7.66 \%$ & $5.61 \%$ & - \\
\hline 6. & (+) Camphor & 152 & $30.62 \%$ & $12.07 \%$ & - \\
\hline 7. & Neral (z- citral) & 152 & $23.17 \%$ & $10.61 \%$ & $34.78 \%$ \\
\hline 8. & (E)-geranial & 152 & - & $1.42 \%$ & $6.41 \%$ \\
\hline 9. & Citronellol & 154 & - & $1.73 \%$ & - \\
\hline 10. & Geranial (cis-trans citral) & 152 & $31.03 \%$ & $13.69 \%$ & $49.21 \%$ \\
\hline 11. & Linalyl acetate & 196 & - & $1.35 \%$ & - \\
\hline 12. & Campholenic aldehyde & 152 & $7.52 \%$ & - & - \\
\hline 13. & Isopiperitone & 152 & - & - & $6.23 \%$ \\
\hline 14. & Geranyl butyrate & 224 & - & - & $3.37 \%$ \\
\hline
\end{tabular}

Table 4: Variations in chemical composition of lemongrass oil collected from three different locations of India.

\section{Conclusion}

The essential oil samples sourced from various geographical locations evidently prove that there are significant variations observed both in physical and chemical properties. Thus these variations remain the basis of the inconsistency in the composition of natural drug product and proper standardization of the natural sources for its chemical composition is highly required to maintain its consistency. While taking a close look at these wide variations, Kerala can be identified as a spot of well flourished geographical conditions favoring the rich constituency in the natural sources. The climatic conditions and topography are really suitable for the quantitative and qualitative production of herbal sources of drugs.

\section{References}

1. Figueiredo AC, Barroso JG, Pedro LG, Scheffer JJC (2008) Factors affecting secondary metabolite production in plants: volatile components and essential oils. Flavour Fragr J 23: 213-226.

2. Bhattii $\mathrm{H}$, lqbal Z, Chatha SAS, Bukhari IH (2007) Variations in oil potential and chemical composition of Eucalyptus crebra among different districts of PunjabPakistan. Int J Agri Biol 9: 136-138.
3. Nikolic B, Ristic M, Bojovic S, Marin PD (2008) Variability of the needle essential oils of Pinus peuce from different populations in Montenegro and Serbia. Chem Biodiver 5: 1377-1388.

4. De Almeida RR, Souto RN, Bastos CN, Da Silva MH, Maia JG (2009) Chemical variation in Piper aduncum and biological properties of its Dillapiole rich essential oil. Chem Biodiver 6: 1427-1434.

5. Chograni H, Zaouali Y, Rajeb C, Boussaid M (2010) Essential oil variation among natural populations of Lavandula multifida L. (Lamiaceae). Chem Biodiver 7: 933-942.

6. Sladky KK, Swanson CR, Stoskopf MK, Loomis MR, Lewbart GA (2001) Comparative efficacy of tricaine methanesulfonate and clove oil in red pacu (Piaractus bracypomus). Am J Veter Res 62: 337-342.

7. Abdel-Wahhab MA, Aly SE (2003) Antioxidant property of Nigella sativa (black cumin) and Syzygium aromaticum (clove) in rats during aflatoxicosis. Toxicol Lett 25: 218-233.

8. Robenorst J (1996) Production of methoxyphenol-type natural aroma chemicals by biotransformation of eugenol with a new Pseudomonas sp. Appl Microbiol Biotechnol 46: 470-474.

9. Paranagama PA, Abeysekera KH, Abeywickrama K, Nugaliyadde L (2003) Fungicidal and anti-aflatoxigenic effects of the essential oil of Cymbopogon citratus (DC.) Stapf. (Lemongrass) against Aspergillus flavus Link. isolated from stored rice. Lett Appl Microbiol 37: 86-90. 
Citation: Priya ES, Selvan PS, Yavanarajan A (2015) Chemotypic Variation in Clove Oil and Lemongrass Oil Obtained from Three Different Geographical Locations of India. J Pharmacogn Nat Prod 1: 102. doi:10.4172/2472-0992.1000102

10. Oyedele O, Orafidiya LO, Lamikanra A, Olaife JI (2000) Volatility and Mosquito Repellency Ofhemizygia Welwitschii Oil and its Formulation. International Journal of Tropical Insect Science 20.

11. Toncer O, Karaman S, Kizil S, Diraz E (2009) Changes in essential oil composition of oregano (Origanum onites L.) due to diurnal variations at different development stages. Notulae Botanicae Horticulture Agrobotanic Cluj- Napoca 37: 177-181.

12. Aprotosoaie AC, Spac A, Hancianu M, Miron A, Tanasescu VF, et al. (2010) The chemical profile of essential oils obtained from fennel fruits (Foeniculum vulgare Mill.). Farmacia 58: 46-53.

13. Oniga I, Vlase L, Toiu A, Benedec D, Duda M (2010) Evaluation of phenolic acid derivatives and essential oil content in some Melissa officinalis $L$. varieties. Farmacia 58 (6): 764-769.

14. Guan W, Li S, Yan R, Tang S, Quan C (2007) Comparison of essential oils of clove buds extracted with supercritical carbon dioxide and other three traditional extraction methods. Food Chem 101: 1558-1564.
15. Bhuiyan MI, Begum J, Nandi NC, Akter F (2010) Constituents of the essential oil from leaves and buds of clove (Syzigium caryophyllatum (L.) Alston). Afr J Plant Sci 4: 451-454.

16. Jirovetz L, Buchbauer G, Stoilova I, Stoyanova A, Krastanov A, et al. (2006) Chemical Composition and Antioxidant Properties of Clove Leaf Essential Oil. J Agri Food Chem 54: 6303-6307.

17. Katsukawa M, Nakata R, Takizawa Y, Hori K, Takahashi S, et al. (2010). Citral, a component of lemongrass oil, activates PPARa and $y$ and suppresses COX-2 expression. Biochim Biophys Acta 1801: 1214-1220.

18. Silva Cde B, Guterres SS, Weisheimer V, Schapoval EE (2008) Antifungal activity of the lemongrass oil and citral against Candida spp. Braz $\mathrm{J}$ Infec Dis 12: $63-66$

19. Rabbani SI, Devi K, Khanam S, Zahra N (2006) Citral, a component of lemongrass oil inhibits the clastogenic effect of nickel chloride in mouse micronucleus test system. Pak J Pharm Sci 19: 108-113. 